\title{
Comparative evaluation of hydrogel dressing with conventional dressing in diabetic foot ulcers
}

\author{
Chandel U.K. ${ }^{1}$, Thakur B.R. ${ }^{2}$, Gupta A.K. ${ }^{3}$ \\ ${ }^{1}$ Dr. U.K. Chandel, Professor, Department of surgery, ${ }^{2}$ Dr. B.R. Thakur, Assistant professor, Department of CTVS surgery, \\ ${ }^{3}$ Dr. Arun Kumar Gupta, Professor, Department of surgery, All authors are affiliated with IGMC Shimla.(H.P), India.
}

Address for Correspondence: Dr. U.K. Chandel, Professor of Surgery IGMC Shimla. E-mail: ukchandel@gmail.com

\begin{abstract}
Introduction: Diabetic foot is a common problem in this part of the country. In patients with diabetic foot and pressure ulcers, early intervention with biological therapy will either halt progression or result in rapid healing of these chronic wounds. So here we compare the effectiveness of hydrogel dressing versus conventional dressings in the healing of diabetic foot ulcerations in terms of healing rate, safety, and patient satisfaction. Material and methods: Prospective case-control study enrolling 40 patients, divided into two groups. Cases (patients treated with hydrogel) and Controls (patients treated with conventional dressings), with an equal number of patients in each group over 12 months period. Diabetic foots were treated until wound closure, either spontaneously, surgically, or until completion of the 8-week period. Result: $85 \%$ study and $90 \%$ control group patients were between the age of 41-70 years. Male to female ratio in study group and control group was 2.33:1 and $4: 1$ respectively. Duration of stay, amputation rates were statistically significantly reduced as compared to control and after 8 weeks of dressing. In study group complete responders were $80 \%$ and in control group $30 \%$ patients were complete responders. Conclusion: Hydrogel dressings appear to be more effective, safe, and patient satisfactory compared to conventional dressings for the treatment of Diabetic foot.
\end{abstract}

Keywords: Diabetic foot ulcer, infections, conventional dressings, vacuum-assisted closure, wound closure.

\section{Introduction}

Diabetic foot ulcer (DFU)-an umbrella term for foot problems-is the most common, complex and costly sequelae of diabetes mellitus (DM) [1] . Diabetic foot ulcer is defined as a full-thickness wound which is present at a level distal to the ankle in patients with diabetes [2]. Special categories like Charcot neuroarthropathy are also included in the DFD [3]]. Patients with diabetic foot are also more likely to present with other diabetes-related complications such as nephropathy, retinopathy, ischemic heart disease and cerebrovascular disease [4].

In the recent years, apart from the standard wound care, new diabetic ulcer treatment modalities have been developed [5,6]. Surgical debridement is the gold standard method in diabetic foot ulceration. To obtain optimal results, healthy tissue loss should be minimized, foot function should be preserved, and deformities which can precipitate recurrence of ulcers should be prevented [7]. Wet to dry dressing is included in standard wound

Manuscript Received: $05^{\text {th }}$ December 2016

Reviewed: $14^{\text {th }}$ December 2016

Author Corrected: $20^{\text {th }}$ December 2016

Accepted for Publication: $31^{\text {st }}$ December 2016 care and is considered a method for mechanical debridement, since it presents a good debriding effect in removal of the necrotic tissue and wound preparation [8]. In order to minimize irritation and discomfort, adequate moistening of the dressings with normal saline is done when treating granulating wound tissues to avoid trauma and bleeding [8].

Hydrogel dressings are considered the best choice for dry wounds with necrotic eschar. Hydrogels provide fluid and good hydration to dry and slough wounds. Although they are very good at absorbing exudates, they should be avoided in diabetic foot planter ulcers as they may cause maceration of the skin surrounding the wound $[9,10]$.

The burden of DFD is expected to rise in the future; giving that the prevalence of its predisposing factors mainly the diabetic peripheral neuropathy and peripheral limb ischemia are continually increasing [11].

Foot ulcers in people with diabetes are a prevalent and serious global health issue. Wound dressings are regarded as important components of ulcer treatment, with 


\section{Research Article}

clinicians and patients having many different types to choose from including hydrogel dressings. Our study suggests that any type of hydrogel wound dressing is more effective in healing diabetic foot ulcers than other types of dressing or a topical cream containing plant extracts.

\section{Material and Methods}

This prospective study was conducted in the Department of Surgery, IGMC Shimla and included cases of diabetic foot either admitted or attending Surgical OPD over 12 months period w.e.f. $01 / 05 / 2010$ to $30 / 04 / 2011$

Study Design- Prospective case control study.

Inclusion Criteria- Patients more than 18 years with fasting blood glucose level > $126 \mathrm{mg} \%$ or patients with known Diabetes with diabetic foot ulcer of at least 30 days duration were included in the study.

Exclusion Criteria- Patients suffering from a condition that has interfered with wound healing (e.g. carcinoma, vasculitis, connective tissue disease or an immune system disorder), with corticosteroids, immunosuppressive agents, radiation therapy and chemotherapy, known hypersensitivity to any of the dressing components.

Duration of Study- 12 months

Collection of Data- A detailed history, clinical examination and relevant investigations were performed in all patients. Before starting the treatment, patients were made to understand in their local language and informed consent was obtained before randomizing into the two groups.

Group A composed of 20 patients treated with hydrogel and Group B composed of 20 patients treated with conventional dressings. Wounds of all the patients included in the study underwent sharp surgical debridement initially and during subsequent dressing change to remove necrotic tissue and slough. After debridement in the emergency operation theatre, a foambased dressing was applied over the wounds of the study group patients under all aseptic conditions. Hyperglycemia and sepsis were controlled according to standard guidelines.

Treatment Duration- Treatment was given for 8 consecutive weeks until ulcer healed, which ever occurred first.

Evaluation of Response- The two longest perpendicular dimension of the ulcer were recorded at baseline and thereafter (i.e. on 1,2,3,5\& 8) responses were recorded. Any untoward side effect was recorded every week with examination on weeks 1,2,3,5 and 8, and recorded. Follow-up evaluation was completed on weekly basis at each visit

\section{Primary Study End Points}

At the end of study period of 8 weeks, the patients were categorized subjectively as follows:-

1. Complete responder - complete healing of leg ulcer

2. Partial responder $-50 \%$ or greater reduction in the product of the two longest perpendicular diameters from baseline

3. Non-complete responder - less than $50 \%$ reduction in the product of the two longest perpendicular diameter from the baseline

4. Non-responder - no reduction in ulcer area or increase in ulcer area over baseline

Statistical Analysis- Data were entered in SPSS 14 and analyzed. Categorical variables were analyzed by using the Pearson's Chi-square/Fishers exact test.

Two groups were compared using Student's $t$-test. Results were expressed as $n(\%)$. $p$-Values of $<0.05$ were considered to be statistically significant.

\section{Results}

Forty patients of diabetic foot were divided into two groups, study group and control group. Twenty patients who received hydrogel based dressing were labelled as "Study group" and twenty patients who received conventional dressing were labelled as "Control group".

In study group, out of 20 patients, 14 were males and 6 were females. In control group, out of 20 patients 16 were males and 4 were females.

Male to female ratio in study group and control group was 2.33:1 and 4:1 respectively (Table - I).17(85\%) of the patients of study group were between 40-70 year while 18(90\%) were in this age group in control group. (Table1). 
Table-1: Age and sex distribution

\begin{tabular}{|c|c|c|c|c|}
\hline \multirow{2}{*}{ Age (in years) } & \multicolumn{3}{|c|}{ Sex } \\
\cline { 2 - 5 } & \multicolumn{2}{|c|}{+ Study } & Male & Female \\
\cline { 2 - 5 } & Male & Female & 00 & 00 \\
\hline$<30$ & 00 & 00 & 01 & 00 \\
\hline $30-40$ & 01 & 00 & 03 & 01 \\
\hline $41-50$ & 05 & 00 & 02 & 03 \\
\hline $51-60$ & 03 & 04 & 09 & 00 \\
\hline $61-70$ & 04 & 01 & 01 & 00 \\
\hline $71-80$ & 01 & 01 & 16 & 04 \\
\hline
\end{tabular}

Table-2: Ulcer distribution

\begin{tabular}{|c|c|c|c|c|c|}
\hline \multirow{2}{*}{} & \multirow{2}{*}{ No. of patients } & \multicolumn{2}{|c|}{ Single ulcer } & \multicolumn{2}{c|}{ Multiple ulcers } \\
\cline { 3 - 6 } & & Study group & Control group & Study group & Control group \\
\hline Male & 30 & 13 & 15 & 02 & 00 \\
\hline Female & 10 & 04 & 04 & 01 & 01 \\
\hline Total & 40 & 17 & 19 & 03 & 01 \\
Total no of ulcers & 44 & 17 & 19 & 6 & 2 \\
\hline
\end{tabular}

All 20 patients in study and control group presented with ulcer. In study group 17 patients presented with single ulcer while 3 patients presented with multiple ulcers. In control group 19(95\%) patients presented with single ulcer while 1 patients presented with multiple ulcers.

Multiple ulcers were present in 4 male and 4 female patients in study group and only in 1 male and 1 female patient in control group. All the multiple ulcer patients had 2 ulcers each. Thus, 20 patients in study group presented with 23 ulcers and 20 patients in control group presented with 21 ulcers. None of the patients had bilateral ulcers.

Table-3: Amputation table

\begin{tabular}{|c|c|c|}
\hline Amputation & Study & Control \\
\hline Digits & 3 & 3 \\
\hline Forefoot & 00 & 1 \\
\hline Bka & 00 & 1 \\
\hline Aka & 00 & 00 \\
\hline
\end{tabular}

In the present study 3 of the total study group underwent amputation while 5 of the control group underwent amputations.

Out of the total of 8 amputations 3 in study and 3 in control group were made due to gangrene

Table-4: End point of study in terms of response

\begin{tabular}{|c|c|c|c|c|c|c|c|c|c|c|}
\hline & \multicolumn{2}{|c|}{ First wk } & \multicolumn{2}{c|}{$\begin{array}{c}\text { Second } \\
\text { wk }\end{array}$} & \multicolumn{2}{c|}{$\begin{array}{c}\text { Third } \\
\text { wk }\end{array}$} & \multicolumn{3}{c|}{$\begin{array}{c}\text { Fifth } \\
\text { wk }\end{array}$} & \multicolumn{2}{c|}{$\begin{array}{c}\text { Eighth } \\
\text { Wk }\end{array}$} \\
\cline { 2 - 12 } & S & C & S & C & S & C & S & C & S & C \\
\hline Complete Patients & 00 & 00 & 03 & 01 & 06 & 02 & 12 & 05 & 14 & 06 \\
response (\%) & 0 & 0 & 15 & 5 & 30 & 10 & 60 & 25 & 70 & 30 \\
\hline Partial Patients Response & 10 & 05 & 11 & 06 & 09 & 06 & 03 & 10 & 03 & 09 \\
$(\%)$ & 50 & 25 & 55 & 30 & 45 & 35 & 15 & 50 & 15 & 45 \\
\hline Non-complete Patients & 07 & 07 & 03 & 06 & 03 & 05 & 02 & 03 & 01 & 03 \\
Response (\%) & 35 & 35 & 15 & 30 & 15 & 25 & 10 & 15 & 05 & 15 \\
\hline Non-responder Patients & 03 & 08 & 02 & 07 & 02 & 07 & 02 & 03 & 01 & 02 \\
Response (\%) & 15 & 40 & 10 & 35 & 10 & 35 & 10 & 15 & 5 & 10 \\
\hline
\end{tabular}


Research Article

After 1st week of dressing, in study group partial and non complete responders were 10 and 7 respectively. In control group, 5 patients were partial responders and 7 patients were non complete responders and 8 were non responders (Table - 12). After 2nd week of dressing, in study group complete responders were 3, partial responders were 11, non complete responder was 2 and non responders were 2. In control group 7 patients were partial responders and 6. After 3rd week of dressing, in study group complete responders were 6 and partial responders were 9 , non complete responders being just one along with 2 non responders. In control group 2 patient was complete responder, 6 were partial responders and 5 were non complete responders with 7 non responders.

After 5th week of dressing, in study group complete responders were 12 and partial responders were 3 . There was 1 non complete and 1 non responder. In control group 5 patients were complete responders, 10 were partial responders and 3 were non complete responder along with 3 non responders. After 8th week of dressing, in study group complete responders were 14 and partial responders were 3 with a single non complete responder. In control group 6 patients were complete responders and 9 were partial responders. There were 3(15\%) non complete responders and 2 non responders.

\section{Discussion}

Hyperglycemia, impaired immunologic responses, neuropathy, and peripheral arterial disease are the major predisposing factors leading to limb-threatening diabetic foot infections [12,13]. The prevalence of infection in India was $6 \%-11 \%$, whereas the prevalence of amputation was $3 \%$ in patients with type 2 diabetes [14]. Both aerobic and anaerobic bacteria have been shown to infect diabetic foot wounds [15-18]. Fungal infections are also common in diabetic foot [19-21]. Polymicrobial etiology of diabetic foot infections has been widely reported [15$18,22]$. However it is not uncommon to have a predominance of mono-microbial infection in diabetic foot [23].

This dressing has a good debriding action and helps in wound bed preparation. Wet-to-dry dressings are described in the literature as a means of mechanical debridement [24]. It is very absorptive as well as adherent and one of the cheapest dressings used throughout the world, but requires frequent dressing change (twice or thrice a day) based on wound severity. Dressings should be moistened before removal to minimize any chance of bleeding. A gentle cleanser (normal saline or neutral-pH cleanser) will minimize wound irritation and discomfort [24]. When treating a granulating or epithelizing wound one should soak the dressing thoroughly with normal saline for five minutes (based on our clinical experience) to prevent trauma and heavy bleeding.

These dressings consist of cross-linked insoluble starch or carboxymethylcellulose polymers and water $(96 \%)$. The term hydrogel implies that the material is already swollen in water. Hydrogels donate fluid to dry necrotic and slough wounds and promote autolysis. They apparently debride by rehydrating the wound. These dressings are the best choice for the treatment of dry wounds with necrotic eschar, and the hydrogel reaches a 50\% debridement level more quickly than wet-to-dry dressings and are more costeffective[25,26]. The hydrogel hydrates, cools the wound and provides an analgesic effect [26].
In our study $85 \%$ cases and $90 \%$ control group patients were between the age of 41-70 years. Male to female ratio in study group and control group was 2.33:1 and 4:1 respectively, similar studies done by Khemariya et al [27] and srinidhi $R$ [28] they studied in two group of patients case Group and Conventional group. Male and female both were selected for treatment. Out of 85 patients 39 was Diabetic foot ulcer class and 30 patients were post burn class, 38 patients were over 40 years old.

In our study we found The diabetic foot ulcer healing rates were statistically significantly higher in study group in comparision to the control group in the first 5 weeks (p value being $0.012,0.015,0.025$ and 0.049 in the first, second, third and fifth week respectively). The results in healing were not significantly different in the two groups after 8 weeks duration, $\mathrm{p}$ value being 0.574 in the eighth week. Similar results also found by Lone et al [28] and Ravari Het al [29].

Present study showed that amputation rates in lower limb was significantly reduced in study than control group $\mathrm{p}=0.049$. Similarly Ali $\mathrm{Z}$ et al[30] study showed comparable wound reduction capabilities with an average wound size reduction of $56 \%$ in comparison to conventional dressing group which had average wound size reduction of $29 \%$. Majority of wounds in VAC group got closed in 7 weeks. Patient satisfaction was excellent in the majority of patients in VAC group compared to those in conventional dressing group.

Ross L et al [31] NPWT was found to be more effective in treating diabetic foot wounds compared with conventional wound dressings. NPWT was quicker at forming granulation tissue, achieving wound closure, removing infection from foot ulcer beds and decreasing wound dimensions. Data also showed greater incidence of amputations in those patients treated with moist wound dressings. 
Diabetic foot ulceration is generally preventable. The first step in ulcer prevention is the careful screening for foot problems and detection of patients at high risk. More research is still required to improve the diagnosis of conditions leading to foot ulceration. Diversity in the diagnostic criteria and the lack of cut off hinders the standardization of management plans. Multi-disciplinary team approach is required to effectively manage the different aspects of diabetic foot syndrome [32].

Present study showed that duration of stay in hospital in study patients was statistically significantly reduced as compared to control study population $\mathrm{p}=0.011$. The mean duration of stay in study group was 19.3 days and 29.5 days in control group patients respectively. Cochrane study [33] included five studies (446 participants) in this review.

Meta analysis of three studies comparing hydrogel dressings with basic wound contract dressings found significantly greater healing with hydrogel: risk ratio (RR) $1.80,95 \%$ confidence interval (CI) 1.27 to 2.56 . The three pooled studies had different follow-up times (12 weeks, 16 weeks and 20 weeks) and also evaluated ulcers of different severities (grade 3 and 4; grade 2 and grade unspecified).

One study compared a hydrogel dressing with larval therapy and found no statistically significant difference in the number of ulcers healed and another found no statistically significant difference in healing between hydrogel and platelet-derived growth factor. There was also no statistically significant difference in number of healed ulcers between two different brands of hydrogel dressing. All included studies were small and at unclear risk of bias and there was some clinical heterogeneity with studies including different ulcer grades.

Diabetes, a condition which leads to high blood glucose concentrations, is a common condition with around 2.8 million people affected in the UK (approximately $3 \%$ of the population). Dressings are a widely used treatment when caring for foot ulcers in people with diabetes. There are many types of dressings that can be used, which also vary considerably in cost. This review (five studies involving a total of 446 people) suggests that hydrogel dressings may be more effective than basic wound contact dressings in healing foot ulcers in people with diabetes although the original research may be biased [33].

\section{Conclusion}

While selecting wound care materials one should bear in mind the properties of the ideal wound care dressing which should maintain a moist wound healing environment, absorb exudates, control infection/odor and be effective in treating diabetic foot wounds. It is concluded that hydrogel dressing is safe, convenient and cost effective in early healing of diabetic foot ulcers and reduced hospital stay and amputation rates.

Diabetic foot ulceration is generally preventable. The first step in ulcer prevention is the careful screening for foot problems and detection of patients at high risk. More research is still required to improve the wound healing of diabetic foot. Standard wound care is recommended, while modern treatment modalities have shown some promising results in recent studies.

Funding: Nil, Conflict of interest: None initiated, Permission from IRB: Yes

\section{References}

1. Singh N, Armstrong DG, Lipsky BA. Preventing foot ulcers in patients with diabetes. JAMA. 2005 Jan 12;293(2):217-28.

2. Apelqvist J, Bakker K, van Houtum WH, NabuursFranssen MH, Schaper NC. International consensus and practical guidelines on the management and the prevention of the diabetic foot. International Working Group on the Diabetic Foot. Diabetes Metab Res Rev. 2000;16 Suppl 1:S84-S92.

3. Rathur HM, Boulton AJ. The diabetic foot. Clin Dermatol. 2007;25:109-120.

4. Khanolkar MP, Bain SC, Stephens JW. The diabetic foot. QJM. 2008 Sep;101(9):685-95. doi: 10.1093/qjmed/hcn027. Epub 2008 Mar 18.

5. Queen D, Orsted H, Sanada H, Sussman G. A dressing history. Int Wound J. 2004 Apr;1(1):59-77.

6. Sibbald RG, Torrance G, Hux M, Attard C, Milkovich N. Cost-effectiveness of becaplermin for nonhealing neuropathic diabetic foot ulcers. Ostomy Wound Manage. 2003 Nov;49(11):76-84.

7. Steed DL, Donohoe D, Webster MW, Lindsley L. Effect of extensive debridement and treatment on the healing of diabetic foot ulcers. Diabetic Ulcer Study Group. J Am Coll Surg. 1996 Jul;183(1):61-4.

8. McDonald A, Lesage P. Palliative management of pressure ulcers and malignant wounds in patients with advanced illness. J Palliat Med. 2006 Apr;9(2):285-95.

9. Schultz GS, Sibbald RG, Falanga V, Ayello EA, Dowsett C, Harding K, Romanelli M, Stacey MC, Teot L, Vanscheidt W. Wound bed preparation: a systematic 


\section{Research Article}

approach to wound management. Wound Repair Regen. 2003 Mar;11 Suppl 1:S1-28.

10. Trudgian J. Investigating the use of Aquaform Hydrogel in wound management. Br J Nurs. 2000 Jul 27Aug 9;9(14):943-8.

11. Intensive blood-glucose control with sulphonylureas or insulin compared with conventional treatment and risk of complications in patients with type 2 diabetes (UKPDS 33). UK Prospective Diabetes Study (UKPDS) Group. Lancet. 1998 Sep 12;352(9131):837-53.

12. Lipsky BA. A report from the international consensus on diagnosing and treating the infected diabetic foot. Diabetes Metab Res Rev. 2004 May-Jun;20 Suppl 1:S6877.

13. Lipsky BA, Berendt AR, Deery HG, Embil JM, Joseph WS, Karchmer AW, LeFrock JL, Lew DP, Mader JT, Norden C, et al. Diagnosis and treatment of diabetic foot infections. Clin Infect Dis. 2004 Oct 1;39(7):885910. Epub 2004 Sep 10.

14. Vishwanathan V, Thomas N, Tandon N, Asirvatham A, Rajasekar S, Ramachandran A, Senthilvasan K, Murugan VS, Muthulakshmi Profile of diabetic foot complications and its associated complications - a multicentric study from India. J Assoc Physicians India. 2005;53:933-936.

15. Anandi C, Aaguraja D, Natarajan V, Ramanatham M, Subramaniam CS, Thulasiram M, Sumithra S. Bacteriology of diabetic foot lesions. Indian J Med Microbiol. 2004 Jul-Sep;22(3):175-8.

16. Gadepalli R, Dhawan B, Sreenivas V, Kapil A, Ammini AC, Chaudhry R. A clinico-microbiological study of diabetic foot ulcers in an Indian tertiary care hospital. Diabetes Care. 2006 Aug;29(8):1727-32.

17. Citron DM, Goldstein EJ, Merriam CV, Lipsky BA, Abramson MA. Bacteriology of moderate-to-severe diabetic foot infections and in vitro activity of antimicrobial agents. J Clin Microbiol. 2007;45:28192828 .

18. Ramakant P, Verma AK, Misra R, Prasad KN, Chand G, Mishra A, Agarwal G, Agarwal A, Mishra SK. Changing microbiological profile of pathogenic bacteria in diabetic foot infections: time for a rethink on which empirical therapy to choose? Diabetologia. 2011;54:5864.
19. Abdulrazak A, Bitar ZI, Al-Shamali AA, Mobasher LA. Bacteriological study of diabetic foot infections. J Diabetes Complications. 2005 May-Jun;19(3):138-41.

20. Raja NS. Microbiology of diabetic foot infections in a teaching hospital in Malaysia: a retrospective study of 194 cases. J Microbiol Immunol Infect. 2007 Feb;40(1):39-44.

21. Bansal E, Garg A, Bhatia S, Attri AK, Chander J. Spectrum of microbial flora in diabetic foot ulcers. Indian J Pathol Microbiol. 2008 Apr-Jun;51(2):204-8.

22. Singh SK, Gupta K, Tiwari S, Shahi SK, Kumar S, Kumar A, Gupta SK. Detecting aerobic bacterial diversity in patients with diabetic foot wounds using ERIC-PCR: a preliminary communication. Int $\mathrm{J}$ Low Extrem Wounds. 2009;8:203-208.

23. Tiwari S, Pratyush DD, Dwivedi A, Gupta SK, Rai M, Singh SK. Microbiological and clinical characteristics of diabetic foot infections in northern India. J Infect Dev Ctries. 2012 Apr 13;6(4):329-32.

24. McDonald A, Lesage P. Palliative management of pressure ulcers and malignant wounds in patients with advanced illness. J Palliat Med. 2006 Apr;9(2):285-95.

25. Schultz GS, Sibbald RG, Falanga V, Ayello EA, Dowsett C, Harding K, Romanelli M, Stacey MC, Teot L, Vanscheidt W. Wound bed preparation: a systematic approach to wound management. Wound Repair Regen. 2003 Mar;11 Suppl 1:S1-28.

26. Trudgian J. Investigating the use of Aquaform Hydrogel in wound management. Br J Nurs. 2000 Jul 27Aug 9;9(14):943-8.

27. Richa Khemariya Prashant Khemariya Comparative evaluation of efficacy of pure collagen type I based modern dressing with conventional dressing in the treatment of burn and diabetic foot ulcer. Int.J.Curr.Res.Med.Sci.(2016).2(2):1-10.

28. Ali M. Lone, MS, ${ }^{1}$ Mohd I. Zaroo, Vacuum-assisted closure versus conventional dressings in the management of diabetic foot ulcers: a prospective case-control study Diabet Foot 2014; 5: 10.3402/dfa.v5.23345.

29. Ravari H, Modaghegh MH, Kazemzadeh GH, Johari HG, Vatanchi AM, Sangaki A, Shahrodi MV. Comparision of vacuum-asisted closure and moist wound dressing in the treatment of diabetic foot ulcers. J Cutan Aesthet Surg. 2013 Jan;6(1):17-20. doi: 10.4103/09742077.110091. 


\section{Research Article}

30. Ali Z, Anjum A, Khurshid L, Ahad H, Maajid S, Dhar SA. Evaluation of low-cost custom made VAC therapy compared with conventional wound dressings in the treatment of non-healing lower limb ulcers in lower socioeconomic group patients of Kashmir valley. J Orthop Surg Res. 2015 Dec 10;10:183. doi: 10.1186/s13018-015-03145.

31. Yarwood-Ross L, Dignon AM. NPWT and moist wound dressings in the treatment of the diabetic foot. Br J Nurs. 2012 Aug 9-Sep 12;21(15):S26, S28, S30-2.
32. Noha Amin, John Doupis Diabetic foot disease: From the evaluation of the "foot at risk" to the novel diabetic ulcer treatment modalities World J Diabetes. 2016 Apr 10; 7(7): 153-164. Published online 2016 Apr 10.

33. Dumville JC, O'Meara S, Deshpande S Hydrogel dressings for healing diabetic foot ulcers (Review) Cochrane database of systematic reviews (Online) 9(9):CD009101 · May 2011

\section{How to cite this article?}

Chandel U.K., Thakur B.R ${ }^{2}$, Gupta A.K. Comparative evaluation of hydrogel dressing with conventional dressing in diabetic foot ulcers . Int J surg Orthopedics 2016;2(4):60-66.doi:10.17511/ijoso.2016.i4.02. 